\section{DARENTH SMALL-POX CAMPS.}

\section{To the Editor of THE LANCET.}

SIR,-In consequence of the discussion now going on in the public journals, both general and professional, regarding the Darenth Small-pox Camps, and the conflicting statements therein contained, I determined to visit them myself, alike in the interests of the metropolitan ratepayers as in the cause of truth and humanity, in order to ascertain by a complete and careful investigation the present real state of things there. I may premise that my visit was totally unexpected, and that not a single member of the Metropolitan Asylums Board was personally known to me. Having during a continuous period of twenty years in the Indian Medical Service had considerable practical experience of camp management, both military and civil, as field hospitals, and camps for epidemics of cholera and gaol fevers in particular, and having been during the last four years of my sojourn there superintendent of the Ráwalpindi gaol-one of the largest, and having an average of over 1000 prisoners daily,-I thought I might venture to form an approximately accurate opinion upon the subject.

I arrived at the camps-there are two, one for males and juveniles over ten years of age, the other for females and children, and some three hundred yards apart-at noon, and spent about four hours there, designedly timing my visit so as to be present during the midday meal. 1 examined and tasted the meat (roast beef), potatoes, pudding (baked currant), the broth and beef-tea, the breadand-butter, and also the beer, and I found them all, both in quantity and quality, good and well cooked; each patient had also some greens, and those who did not wish for beer were allowed milk-and-water, lemonade, or ginger-beer. The quantity of meat I considered superabundant; there was no fixed quantity, each being allowed to take as much of everything as desired; and I saw with much regret large quantities of beef and mutton, the remains of joints, cast into a tub to be eventually cremated, being informed by the superintendent, Dr. Waylen, and the steward, Mr Harper, who with a solicitor, specially, and equally unexpectedly, deputed by the Asylums Board to examine into the complaints which have lately appeared in print, accompanied me throughout my searching inspection, that there was no other way of disposing of it.

I afterwards visited the sleeping tents, examined the bedding, the pillows, mattresses, \&c., which are filled with horsehair, as well as the personal clothing of many of the inmates, and found them all clean, suitable, abundant, and of superior quality; indeed, in this latter respect, in my opinion, extravagantly so. I also visited the kitchens, the general stores, laundry, bath-room, the disinfecting and engine rooms, as well as examined the sanitary, and especially the conservancy arrangements - the dry-earth system is universal,-the drainage, and the water-supply, and found them all satisfactory. The infirmaries-three, one each for the males, females, and children--I particularly inspected; they are substantial wooden structures, and in cleanliness, order, lighting, and temperature, all that can be expected. I may here state that all the tents and wooden sheds are warmed by means of steam-pipes, and that a suitable temperature, superintended by special attendants night and day, is regularly maintained. During my visit a batch of twenty women and children had just arrived from the ships near Dartford; they were conveyed in a threehorse omnibus, and, although they had travelled during a severe snowstorm, they arrived in a comfortable condition, and their clothing was in every way suitable. All the patients throughout the camps appeared happy and comfortable. I spoke to many of them, of all ages and of both sexes, and they all expressed themselves satisfied; indeed, although in all the places visited the question was loudly asked, there were no complaints; but on our leaving the mess-room of the male patients we were dismissed with loud, lusty, and repeated cheers, which were audible at some distance outside after we left.

In short, the condition of all the patients seemed in all respects highly creditable to the local authorities; and I noticed particularly the respectable appearance and gentle demeanour of the subordinate establishment, especially of the female nurses. The patients are provided with books, games, and gymnastic apparatus, and there are entertainments-such as singing, recitations, \&c.-every evening in the assembly-rooms. Toys and suitable picture-books are also provided for the children; and the scale of diet throughout seems to be a liberal one. The total number of patients was 658 . The number of sleeping tents was thirtyfive; all of them very large and lofty, having double flys, and standing upon raised brick pillars, about three feet high. They are provided with wooden flooring, and the superintendent has adopted, of his own design, and for all of them, glazed doors, giving them the cheerful appearance and lightness of an ordinary dwelling. The estate on which the camps are pitched consists of about 300 acres; the site is ample, sloping, well sheltered by the adjoining Darenth wood, and overlooks some of the most beautiful scenery in the country. It is about 400 yards from the main road, and from the three or four residences about it; the inhabitants of which are thus completely insured against the possibility of being contagiously affected. The establishment appears ample and efficient. The superintendent seems entirely devoted to his somerwhat disagreeable duties, and he is assisted by two fully qualified assistants.

There appears to me to be no grounds whatever for any anxiety regarding the welfare of these poor and unfortunate patients, whose condition has naturally excited the sympathetic solicitude of the general public, and the managers of the asylums board deserve the highest praise and the best thanks of the community for their efforts in so rapidly organising this large and novel institution. I am, Sir, yours truly,

JoHN INCE, M.D.,

Jan. 12th, 1885. H.M.'s Indian Medical Service, Retired List.

\section{TUBERCLE BACILLI AT THE ROYAL MEDICAL AND CHIRURGICAL SOCIETY.}

To the Editor of THE LANCET.

Sin,-As I was prevented by the rules of debate from speaking again in the discussion on tubercle bacilli at the Medical and Chirurgical Society on Tuesday evening last, perhaps you will kindly allow me a few lines of your space to say that I heard nothing from $\mathrm{Mr}$. Watson Cheyne which directly met my statements and inquiries made at the previous meeting. We are still left in doubt as much as ever whether Dr. Koch strictly adheres to the fractional principle in his cultivations. In one passage of his report to the Association for the Advancement of Medicine by Research, Mr. Cheyne would have us believe that the fractional principle was adhered to by Dr. Koch throughout a long succession of cultivations, although Dr. Koch himself withholds the detailed information on that point, not only in his first paper, but equally in his final reports of eighteen months' later date. In another passage Mr. Cheyne implies that the whole of the first cultivation was transferred to the second test-tube, "and so on." In his remarks on Tuesday evening, he seemed to treat the quantity of scales or crusts carried forward as a matter of indifference, and even of uncertainty. But everyone knows that the very principle of the pure cultivation of fungi which was introduced by Brefeld (and which I saw applied to diseaseproducing fungi by Dr. Grawitz at Berlin eight years ago) is to make each successive crop of organisms grow from the smallest possible fraction of the former crop.

It is needless for me to meet Mr. Cheyne's round assertion that I am from first to last in error. My printed statements as to matters of fact are all authenticated by references, and they are not to be overthrown by a display of virtuous indignation. As to my interposition in this business, I do no more than exercise the right and duty of every member of the profession to hold and express an intelligent opinion on a disease which confronts us every day.

I am, Sir, your obedient servant,

C. CREIGHTON, M.D.

New Cavendish-street, W., Jan. 14th, 1885.

\section{COCAINE AS A LOCAL AN AESTHETIC.}

\section{To the Editor of THE LANCET.}

SIR,- Evidence of the value of cocaine is so rapidly accumulating that additional testimony seems scarcely required. I should, however, be glad to add a few lines to my letter which you published on Nov. 22nd. I have continued to use it in varying quantities for many purposes, and seldom without satisfactory results. Ophthalmic 